\title{
Local uniqueness solution of illuminated solar cell intrinsic electrical parameters
}

\author{
Abdennaceur Jarray ${ }^{1}$, Mahdi Abdelkrim ${ }^{1,2^{*}}$, Mohamed Bouchiba ${ }^{1,2}$ and Abderrahman Boukricha ${ }^{1}$
}

\begin{abstract}
Starting from an electrical dissipative illuminated one-diode solar cell with a given model data at room temperature $\left(I_{s c}, V_{o c}, R_{s O}, R_{s h o,} I_{\text {max }}\right)$; we present under physical considerations a specific mathematical method (using the Lambert function) for unique determination of the intrinsic electrical parameters $\left(n, I_{s,} I_{p h}, R_{s,} R_{s h}\right)$. This work proves that for a given arbitrary fixed shunt resistance $R_{s h}$, the saturation current $I_{s}$ and the ideality factor $n$ are uniquely determined as a function of the photocurrent $I_{p h}$, and the series resistance $R_{s}$. The correspondence under the cited physical

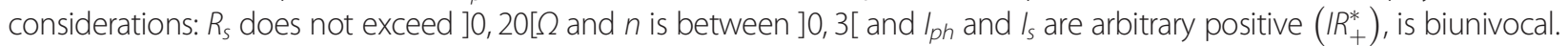
This study concludes that for both considered solar cells, the five intrinsic electrical parameters that were determined numerically are unique.
\end{abstract}

Keywords: Solar cell model; Electrical parameters; Electrical characterization; Lambert function; Shokley's equation; Numerical modeling

\section{Introduction}

Although the electrical dissipative one diode model has a potential of improvement in the efficiency and the stability of the solar cell structure under illumination, to our knowledge the uniqueness and the authenticity of the extracted intrinsic electrical parameters associated to the model have not been studied previously.

In this work we attempt to develop this concept and prove the uniqueness of the determination of these parameters.

The one-diode model gives sufficient efficiency for earthly applications (Charles 1984). A precise numerical method using this model was presented in the early 1980s by Charles et al. $(1981 ; 1985)$.

The use of the Lambert W-Function proposed by Corless et al. (1996) allowed demonstrating explicitly the Shokley's modified eq. (1) which is related to the equivalent electrical circuit model as shown in Figure 1.

$$
I=I_{p h}-\frac{V+R_{s} I}{R_{s h}}-I_{s}\left[\exp \left(\frac{q\left(V+R_{s} I\right)}{n k T}-1\right]\right.
$$

\footnotetext{
* Correspondence: mahdi.abdelkrim@planet.tn

'Unité de recherche: Optimisation Appliquée, Faculté des Sciences de Tunis, Campus Universitaire, 1060 Tunis, Tunisie

${ }^{2}$ Instiut National des Sciences Appliquées et de Technologie, Centre urbain Nord de Tunis, BP 676, 1080 Tunis, Tunisie
}

Where $I_{p h}$ is the photocurrent, $n$ is the diode ideality factor of the junction, $I_{s}$ is the reverse saturation current, $R_{s}$ is the series resistance and $R_{s h}$ is the shunt resistance.

Each of these parameters is connected to the suited internal physical mechanism acting within the solar cell. Their knowledge is therefore important.

Several methods were proposed to determine the intrinsic electrical parameters: $I_{p h} ; n ; I_{s} ; R_{s} ; R_{s h}$ presented in eq. (1) of the solar cell. In particular, Jain and Kapoor (2005) established a practical method to determine the diode ideality factor of the solar cell.

Ortiz-Conde et al. (2006) have used a co-content function to determine these parameters. Jain et al. (2006) determine these parameters on solar panels. Chegaar et al. (2006) have used four comparative methods to determine these parameters.

More recently, Kim and Choi (2010) have used another method to determine the intrinsic parameters of the cell by making a remarkable initialization of the ideality factor $n$ and the saturation current $I_{s}$ (Kim \& Choi 2010).

\section{Theoretical study: problem formulation}

To determine the solar cell intrinsic electrical parameters $\left(n, I_{s}, I_{p h}, R_{s}, R_{s h}\right)$, we put together a system of five equations (Lemma 2), and, solved by two different

\section{穴}




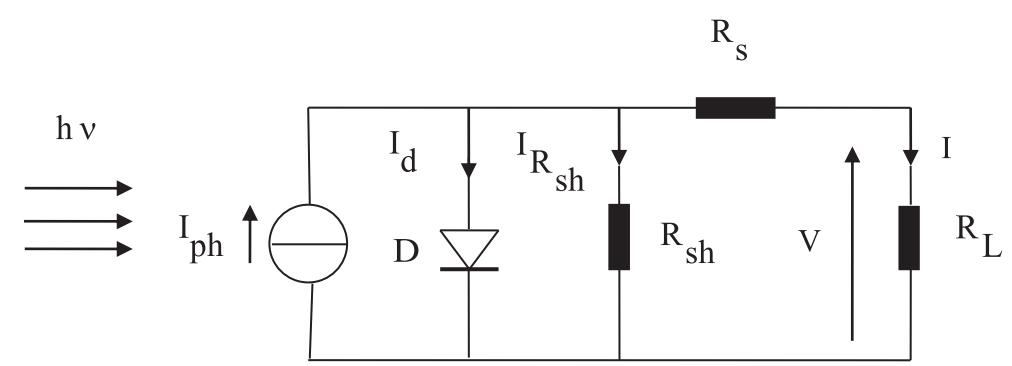

Figure 1 Solar cell one-diode equivalent circuit model, under specified illumination and temperature.

numerical methods. The Lambert W-function is the reverse of the function $\mathrm{F}$ defined from $C_{+}$in $C$ by $F(W)=$ $W e^{W}$ for every $\mathrm{W}$ in $C_{+}$.

Lemma 1: The Lambert W-function was derived from eq. (1) by expressing the current $I$ in function of the voltage $V$ and vice-versa, as follows

$$
\begin{array}{r}
I=\frac{V}{R_{s}+R_{s h}}-\frac{W\left(\frac{R_{s} R_{s h} I_{s} \exp \left(\frac{R_{s h}\left(R_{s}\left(I_{s}+I_{p h}\right)+V\right.}{n V_{T}\left(R_{s}+R_{s h}\right)}\right)}{n V_{T}\left(R_{s}+R_{s h}\right)}\right) n V_{T}}{R_{s}} \\
+\frac{R_{s h}\left(I_{s}+I_{p h}\right)}{R_{s}+R_{s h}} \\
\quad-I\left(R_{s}+R_{s h}\right)+R_{s h} I_{p h} \\
-W\left(\frac{I_{s} R_{s h} \exp \left(\frac{R_{s h}\left(-I+I_{s}+I_{p h}\right)}{n V_{T}}\right)}{n V_{T}}\right) n V_{T}+R_{s h} I_{S}
\end{array}
$$

Figure 2 I (V) characteristics of a solar cell under illumination in generator convention.

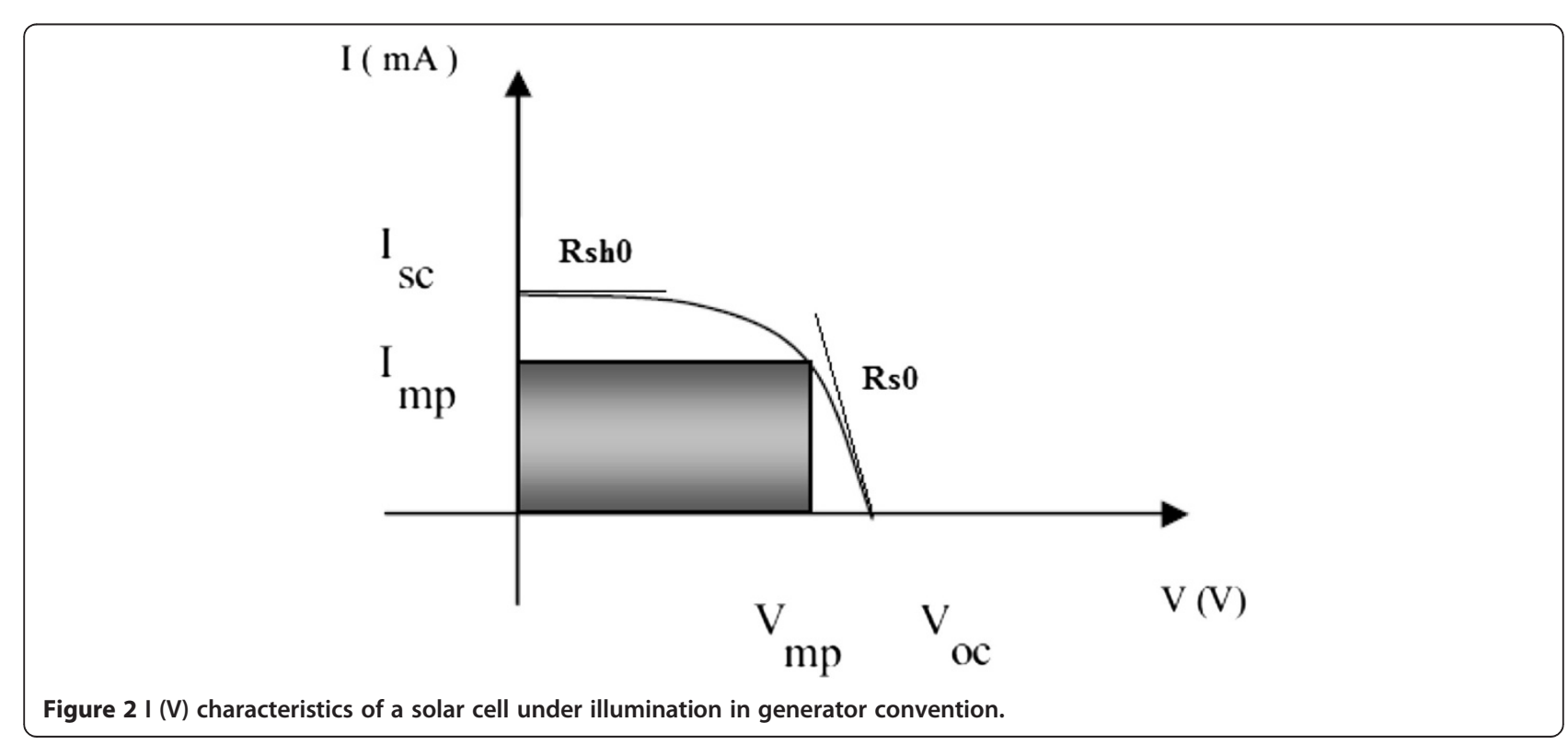

$$
P(I)=I\left(-I\left(R_{s}+R_{s h}\right)+R_{s h} I_{p h}-W\left(\frac{I_{s} R_{s h} \exp \left(\frac{R_{s h}\left(-I+I_{s}+I_{p h}\right)}{n V_{T}}\right)}{n V_{T}}\right) n V_{T}+R_{s h} I_{s}\right)
$$

We consider the following I (V) solar cell characteristics under illumination in generator convention as presented in Figure 2.

Where $I_{s c}$ and $V_{o c}$ represent the short-circuit current and the open-circuit voltage respectively, $R_{s h o}$ is the slope of the I-V curve at the $\left(0, I_{s c}\right)$ point, $R_{s o}$ is the slope of the I-V curve at the $\left(V_{o c}, 0\right)$ point and $I_{\max }$ is the maximum power current, and $I_{p h} I_{s} n, R_{s}$, and $R_{s h}$ are the intrinsic electrical parameters that should be determined.

In order to simplify the problem formulation, we adopt the following abbreviations

$$
\begin{aligned}
& X=\left(I_{s c}, V_{o c}, R_{s 0}, R_{s h o}, I_{\max }\right), Y=\left(n, I_{s}, I_{p h}, R_{s}, R_{s h}\right) \\
& A_{1}=\exp \left(\frac{R_{s h} R_{s}\left(I_{s}+I_{p h}\right)}{n V_{T}\left(R_{s}+R_{s h}\right)}\right), A_{2}=\exp \left(\frac{R_{s h}\left(I_{s}+I_{p h}\right)}{n V_{T}}\right) \\
& A_{3}=\exp \left(\frac{R_{s h}\left(-I_{s c}+I_{s}+I_{p h}\right)}{n V_{T}}\right), A_{4}=\exp \left(\frac{R_{s h}\left(-I_{\max }+I_{s}+I_{p h}\right)}{n V_{T}}\right)
\end{aligned}
$$


From eq. (2) and at the point (0, Isc) we obtained

$$
f_{1}(X, Y)=-\frac{W\left(\frac{R_{s} R_{s h} I_{s} A_{1}}{n V_{T}\left(R_{s}+R_{s h}\right)}\right) n V_{T}}{R s}+\frac{R_{s h}\left(I_{s}+I_{p h}\right)}{R_{s}+R_{s h}}-I_{s c}
$$

Idem from eq. (3) and at the point $\left(\mathrm{V}_{\mathrm{oc}}, 0\right)$ we obtained

$$
f_{2}(X, Y)=R_{s h} I_{p h}-W\left(\frac{I_{s} R_{s h} A_{2}}{n V_{T}}\right) n V_{T}+R_{s h} I_{s}-V_{o c}
$$

The slope at the point $\left(\mathrm{V}_{\mathrm{oc}}, 0\right)$ of the eq. (2) we obtained

$$
f_{3}(X, Y)=-R_{s h} \frac{W\left(\frac{I_{s} R_{s h} A_{2}}{n V_{T}}\right)}{1+W\left(\frac{I_{s} R_{s h} A_{2}}{n V_{T}}\right)}-R_{s 0}+R_{s}+R_{s h}
$$

The slope at the point (0, Isc) of the eq. (2) gives

$$
f_{4}(X, Y)=-R_{s h} \frac{W\left(\frac{I_{s} R_{s h} A_{3}}{n V_{T}}\right)}{1+W\left(\frac{I_{s} R_{s h} A_{3}}{n V_{T}}\right)}-R_{s h 0}+R_{s}+R_{s h}
$$

For differentiating eq. (4) and at the point $\left(I=I_{\max }\right)$ stems

$$
\begin{aligned}
f_{5}(X, Y)= & -W\left(\frac{I_{s} R_{s h} A_{4}}{n V_{T}}\right) n V_{T}+R_{s h} I_{s} \\
& +I_{\max }\left(-R_{s}-R_{s h}+R_{s h} \frac{W\left(\frac{I_{s} R_{s h} A_{4}}{n V_{T}}\right)}{1+W\left(\frac{I_{s} R_{s h} A_{4}}{n V_{T}}\right)}\right) \\
& +I_{\max }\left(R_{s}+R_{s h}\right)+R_{s h} I_{p h}
\end{aligned}
$$

Lemma 2: We have the following system

$$
\left\{\begin{array}{l}
f_{1}(X, Y)=0 \\
f_{2}(X, Y)=0 \\
f_{3}(X, Y)=0 \\
f_{4}(X, Y)=0 \\
f_{5}(X, Y)=0
\end{array}\right.
$$

Proof: For $I=I_{s c}$ and $V=0$, eq. (2) implies that $f_{1}(X, Y)=$ $O$ and for $V=V_{o c}$ and $I=0$ eq. (3) implies that $f_{2}(X, Y)=0$.

The differential resistances: $R_{s O}$ and $R_{s h o}$ lead to the following two equations: $f_{3}(X, Y)=0$ and $f_{4}(X, Y)=0$.

From eq. (4), maximal power obtained by: $\left(\frac{\partial P}{\partial I}\right)_{I=\operatorname{Im} a x}=0$ implies that $f_{5}(X, Y)=0$.

In order to solve the system presented in Lemma 2 (eq. 10) and determine the intrinsic electrical parameters, a set of experimental measurements (data) were used (Table 1).

These measurements were collected from two different solar cells under AM1 illumination $(E=1 \mathrm{~S}=$ $100 \mathrm{~mW} / \mathrm{cm}^{2}$ ) at room temperature.
Table $1 \mathrm{SAT}$ and $\mathrm{Cu}_{2} \mathrm{~S}-\mathrm{CdS}$ cells experimental data

\begin{tabular}{ccc}
\hline Experimental data & SAT cell $(\mathbf{E}=\mathbf{1} \mathbf{~ S )}$ & $\mathbf{C u}_{\mathbf{2}} \mathbf{S}-\mathbf{C d S}$ cell $(\mathbf{E}=\mathbf{1} \mathbf{~ S})$ \\
\hline$V_{\text {oc }}(V)$ & 0.536 & 0.469 \\
$R_{\text {SO }}(\Omega)$ & 0.45 & 6.857 \\
$I_{\text {sC }}(A)$ & 0.1025 & 0.04075 \\
$I_{\max }(A)$ & 0.0925 & 0.025 \\
$R_{\text {sho }}(\Omega)$ & 1000 & 41.905 \\
$V_{T}(V)$ & 0.025875 & 0.023527 \\
\hline
\end{tabular}

Our study concerns p-n junctions at both homo- and hetero-junctions: For the homo-junction, a $4 \mathrm{~cm}^{2}$ blue type monocrystalline silicon cell produced by SAT (1980) was used. For the hetero-junction we have used a frontwall $\mathrm{Cu}_{2} \mathrm{~S}-\mathrm{CdS}$ cell produced by a wet (Cleveite) process with significant losses of $4.28 \mathrm{~cm}^{2}$ square area. Two different numerical methods were applied in order to prove their authenticity.

\section{Numerical approach of the intrinsic parameters Newton's method}

The following function was considered

$$
F(X, Y)=\left(f_{1}(X, Y), f_{2}(X, Y), f_{3}(X, Y), f_{4}(X, Y), f_{5}(X, Y)\right)
$$

Let $\mathrm{J}_{\mathrm{F}}$ denote the Jacobian matrix defined by

$$
J_{F}^{Y}(X, Y)=\left[\frac{\partial f_{i}(X, Y)}{\partial Y_{j}}\right]_{1 \leq i, j \leq 5}
$$

So, Newton's method can be formulated as follows: For $Y^{0}=\left(\mathrm{n}^{0}, \mathrm{I}_{\mathrm{s}}^{0}, \mathrm{I}_{\mathrm{ph}}^{0}, \mathrm{R}_{\mathrm{s}}^{0}, \mathrm{R}_{\mathrm{sh}}^{0}\right)$ as an initial condition and for all $k=0,1 \ldots$ until convergence; we have to resolve the unknown variable $Y^{k}$ using the following system of equations: $J_{F}\left(\mathrm{Y}^{\mathrm{k}}\right) \delta \mathrm{Y}^{\mathrm{k}}=-\mathrm{F}\left(\mathrm{Y}^{\mathrm{k}}\right)$, where: $Y^{k+1}=\mathrm{Y}^{\mathrm{k}}+\delta \mathrm{Y}^{\mathrm{k}}$ and: $Y^{k}=\left(\mathrm{n}^{\mathrm{k}}, \mathrm{I}_{\mathrm{s}}^{\mathrm{k}}, \mathrm{I}_{\mathrm{ph}}^{\mathrm{k}}, \mathrm{R}_{\mathrm{s}}^{\mathrm{k}}, \mathrm{R}_{\mathrm{sh}}^{\mathrm{k}}\right)$.

In order to apply the Newton's method to this system an iterative program was developed in a MAPLE environment Monagan et al. (2003) using an accuracy of 20-digits.

It depends on the choice of the initial data $Y^{\circ}$ by making sure that $J_{F}\left(Y^{\mathrm{k}}\right) \neq 0$ and by continuing the iteration process until a quadratic convergence is reached.

At each increment, the program performs a test between two successive iterations by assessing the Euclidean norm of their difference. The program was designed to stop the calculation when the test reaches a value smaller than the pre-set tolerance value.

\section{Hooke-Jeeves's method}

The Hooke-Jeeves method is based on numerical calculation of the minimum of a function $G$ without the use of gradient. This method is widely used in applications with convex $G$. 


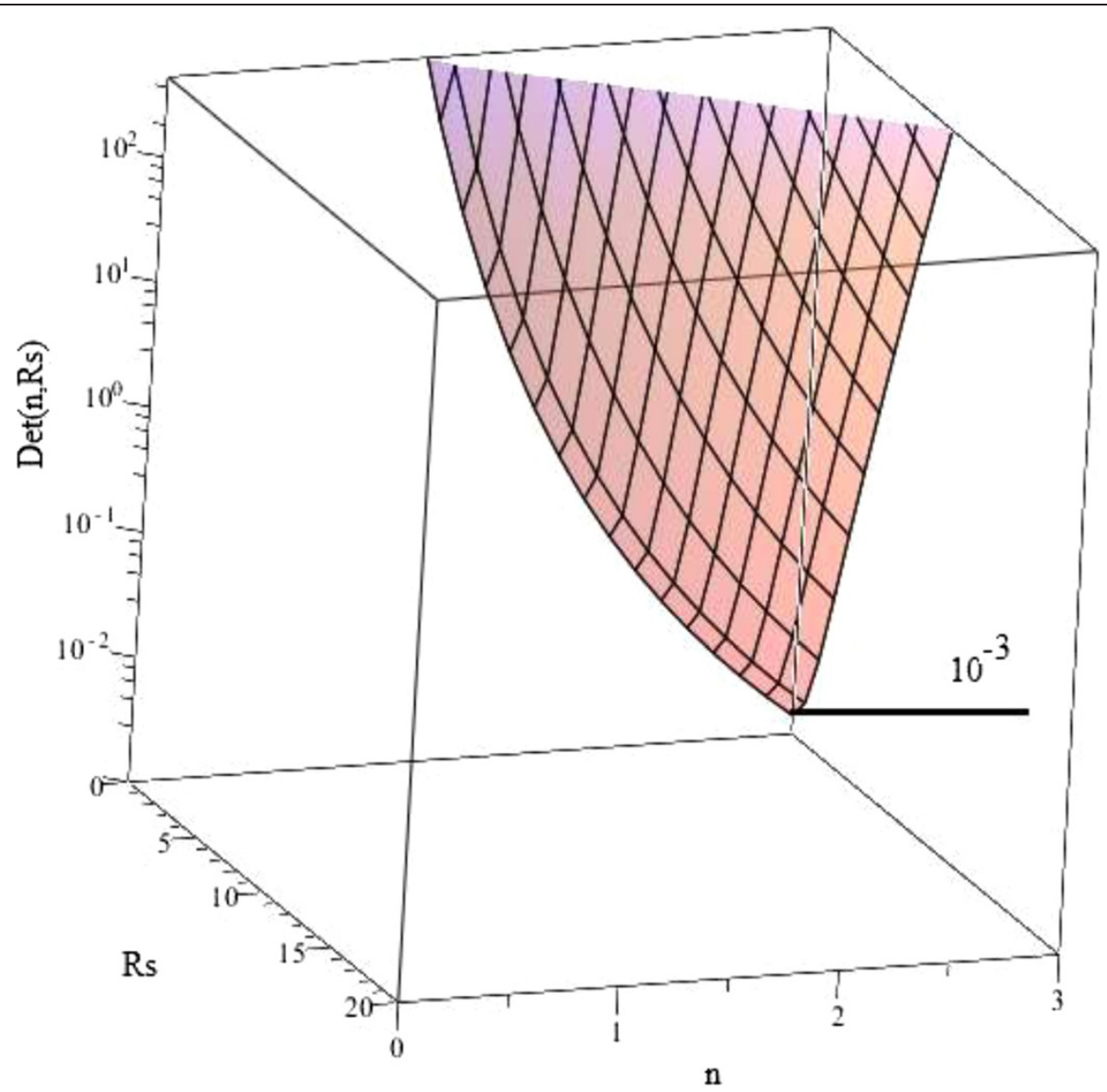

Figure $3 R_{s}$ and $n$ dependences of Det $\left(R_{s}, n\right)$.

This method was used in this study to find the zero of function $G$ (eq. 11) by minimizing in $X$ and $Y$ such that

$$
\begin{aligned}
& G(X, Y)=0 ; G(X, Y)=\left|f_{1}(X, Y)\right|+\left|f_{2}(X, Y)\right| \\
&+\left|f_{3}(X, Y)\right|+\left|f_{4}(X, Y)\right|+\left|f_{5}(X, Y)\right|
\end{aligned}
$$

We recall that $G(X, Y)=0$ is equivalent to the system presented in eq. (9) which leads to the determination of the intrinsic electrical parameters.

This method has the advantage of being easily programmed except the need to calculate gradient $G$.

\section{Existence and uniqueness of the solution}

To determine the existence and the uniqueness of the system presented in lemma 2 (eq. 9), we use the following Table 2 SAT solar cell's intrinsic electrical parameters ( $E=1 \mathrm{~S}$ )

\begin{tabular}{ccc}
\hline Intrinsic parameters & Newton's method & Hooke-Jeeve's method \\
\hline$I_{p h}(A)$ & 0.102502 & 0.102002 \\
$I_{S}(A)$ & $5.987171985 \times 10^{-7}$ & $5.97501 \times 10^{-7}$ \\
$n$ & 1.709464 & 1.721481 \\
$R_{S}(\Omega)$ & 0.016437 & 0.016437 \\
$R_{s h}(\Omega)$ & 1014.244754 & 1000.412260 \\
\hline
\end{tabular}

implicit functions theorem where: $H$ represents a continuously differentiable real-valued functions defined on a domain $D$ in $I R^{2} x I R^{2}$ into $I R^{2}$ :

$$
\begin{aligned}
& H\left(I_{p h}, R_{s}, n, I_{s}\right)=\left(h_{1}\left(I_{p h}, R_{s}, n, I_{s}\right), h_{2}\left(I_{p h}, R_{s}, n, I_{s}\right)\right): \\
& h_{1}\left(I_{p h}, R_{s}, n, I_{s}\right)=-I_{s c}+I_{p h}-\frac{R_{s} I_{S C}}{R_{s h}}-I_{s}\left[\exp \left(\frac{q\left(R_{s} I_{s c}\right)}{n k T}-1\right] ;\right. \text { and } \\
& h_{2}\left(I_{p h}, R_{s}, n, I_{s}\right)=I_{p h}-\frac{V_{o c}}{R_{s h}}-I_{s}\left[\exp \left(\frac{q\left(V_{o c}\right)}{n k T}-1\right]\right.
\end{aligned}
$$

By using the following notations: $A=\left(I_{p h}, R_{s}\right) ; B=\left(n, I_{s}\right)$

Let $J_{H}^{B}(\mathrm{~A}, \mathrm{~B})$ be the following Jacobian matrix: $J_{H}^{B}(\mathrm{~A}, \mathrm{~B})=\left[\frac{\partial \mathrm{h}_{i}(\mathrm{~A}, \mathrm{~B})}{\partial B_{j}}\right]_{1 \leq i, j \leq 2}$

Table 3 Frontwall $\mathrm{Cu}_{2} \mathrm{~S}-\mathrm{CdS}$ solar cell's intrinsic electrical parameters $(\mathrm{E}=1 \mathrm{~S})$

\begin{tabular}{ccc}
\hline Intrinsic parameters & Newton's method & Hooke-Jeeve's method \\
\hline$I_{p h}(A)$ & 0.045528 & 0.045487 \\
$I_{s}(A)$ & $8.2455 \times 10^{-6}$ & $8.0 \times 10^{-6}$ \\
$n$ & 2.183476 & 2.176611 \\
$R_{S}(\Omega)$ & 5.355408 & 5.298477188 \\
$R_{s h}(\Omega)$ & 49.838828 & 49.175974 \\
\hline
\end{tabular}


Table 4 SAT solar cell's calculated I-V values by Hooke's method

\begin{tabular}{cccc}
\hline $\boldsymbol{V}(\boldsymbol{V})$ & $\boldsymbol{I}_{\exp }(\boldsymbol{A})$ & $\boldsymbol{I}_{\text {Hooke }}(\boldsymbol{A})$ & $\boldsymbol{D}(\%)$ \\
\hline 0.000000 & 0.102500 & 0.102501 & 0.000009 \\
0.100000 & 0.102500 & 0.102396 & 0.001015 \\
0.150000 & 0.102500 & 0.102333 & 0.001631 \\
0.200000 & 0.102500 & 0.102245 & 0.002494 \\
0.250000 & 0.102500 & 0.102079 & 0.004124 \\
0.300000 & 0.101500 & 0.101669 & 0.001665 \\
0.325000 & 0.101200 & 0.101241 & 0.000405 \\
0.350000 & 0.100500 & 0.100510 & 0.000099 \\
0.375000 & 0.099500 & 0.099246 & 0.002559 \\
0.400000 & 0.09770 & 0.097048 & 0.006718 \\
0.425000 & 0.09450 & 0.093216 & 0.013774 \\
0.450000 & 0.08900 & 0.086533 & 0.028509 \\
0.475000 & 0.07780 & 0.074895 & 0.038787 \\
0.500000 & 0.05750 & 0.054718 & 0.050842 \\
0.536000 & 0.00000 & 0.000000 & 0.000000 \\
\hline
\end{tabular}

Let: $\left(A^{0}, B^{0}\right)$ be a point in $D$ such that $H\left(A^{0}, B^{0}\right)=0$, and $J_{H}^{B}\left(A^{0}, \mathrm{~B}^{0}\right)$ is invertible i.e. $\left(\operatorname{Det}\left(\mathrm{J}_{\mathrm{H}}^{\mathrm{B}}\left(\mathrm{A}^{0}, \mathrm{~B}^{0}\right)\right) \neq 0\right)$.

The last step is to determine the neighborhood $U \times V$ where the following determinant of the Jacobian matrix will remain

$$
\begin{aligned}
\operatorname{Det}\left(J_{H}^{B}(A, B)\right)= & \frac{I_{S}}{n^{2} V_{T}}\left\{V_{o c} \exp \left(\frac{V_{o c}}{n V_{T}}\right)\left(1-\exp \left(\frac{R_{s} I_{s c}}{n V_{T}}\right)\right)\right. \\
& \left.-R_{s} I_{s c} \exp \left(\frac{R_{s} I_{s c}}{n V_{T}}\right)\left(1-\exp \left(\frac{V_{o c}}{n V_{T}}\right)\right)\right\}
\end{aligned}
$$

Table 5 SAT solar cell's calculated I-V values by Newton's method

\begin{tabular}{lccc}
\hline $\boldsymbol{V}(\boldsymbol{V})$ & $\boldsymbol{I}_{\exp }(\boldsymbol{A})$ & $\boldsymbol{I}_{\text {Newton }}(\boldsymbol{A})$ & $\boldsymbol{D}(\%)$ \\
\hline 0.000000 & 0.102500 & 0.102500 & 0.0000000 \\
0.100000 & 0.102500 & 0.102397 & 0.001005 \\
0.150000 & 0.102500 & 0.102337 & 0.001592 \\
0.200000 & 0.102500 & 0.102255 & 0.002395 \\
0.250000 & 0.102500 & 0.102104 & 0.003878 \\
0.300000 & 0.101500 & 0.101739 & 0.002354 \\
0.325000 & 0.101200 & 0.101359 & 0.001571 \\
0.350000 & 0.100500 & 0.100708 & 0.002069 \\
0.375000 & 0.099500 & 0.099580 & 0.000804 \\
0.400000 & 0.09770 & 0.097614 & 0.000881 \\
0.425000 & 0.09450 & 0.094173 & 0.003472 \\
0.450000 & 0.08900 & 0.088149 & 0.009654 \\
0.475000 & 0.07780 & 0.077613 & 0.002409 \\
0.500000 & 0.05750 & 0.059257 & 0.030556 \\
0.536000 & 0.00000 & 0.000000 & 0.000000 \\
\hline
\end{tabular}

Table 6 Frontwall $\mathrm{Cu}_{2} \mathrm{~S}-\mathrm{CdS}$ solar cell's calculated I-V values by Hooke's method

\begin{tabular}{cccc}
\hline $\boldsymbol{V}(\boldsymbol{V})$ & $\boldsymbol{I}_{\exp }(\boldsymbol{A})$ & $\boldsymbol{I}_{\text {Hooke }}(\boldsymbol{A})$ & $\boldsymbol{D}(\%)$ \\
\hline 0.000000 & 0.0408000 & 0.041010 & 0.0051470 \\
0.050000 & 0.0393 & 0.039746 & 0.011348 \\
0.100000 & 0.0373 & 0.038120 & 0.021983 \\
0.200000 & 0.0315 & 0.032689 & 0.037746 \\
0.250000 & 0.0273 & 0.028445 & 0.041941 \\
0.275000 & 0.0250 & 0.025929 & 0.037160 \\
0.300000 & 0.0225 & 0.023173 & 0.029911 \\
0.325000 & 0.0196 & 0.020201 & 0.030663 \\
0.350000 & 0.0165 & 0.017038 & 0.032606 \\
0.375000 & 0.0132 & 0.013705 & 0.038257 \\
0.400000 & 0.0099 & 0.010225 & 0.032828 \\
0.450000 & 0.0025 & 0.002895 & 0.158000 \\
0.469000 & 0.000000 & 0.000000 & 0.000000 \\
\hline
\end{tabular}

This determinant does not depend on $I_{p h}$ and is linear with $I_{s}$. The $R_{s}$ and $n$ dependences of the determinant are illustrated in the following figure (Figure 3).

The minimum of the determinant in ] $0,20[x] 0,3$ [ is $10^{-3}$. Consequently the investigated neighborhood $U \times$ $V$ is $\left.\operatorname{IR}_{+}^{*} \times\right] 0,20[\times] 0,3\left[\times \mathrm{IR}_{+}^{*}\right.$.

The implicit functions theorem gives the existence of a unique function $B=\phi$ (A) defined in $U$ into $V$ of class $C^{1}$ and for any $(A, B) \in U \times V, H(A, \phi(A))=0$. As a result the $\varphi$ Jacobian matrix is given by the formula: $J_{\phi}$ $(\mathrm{A})=J_{H}^{B}(\mathrm{~A}, \phi(\mathrm{A}))^{-1} J_{H}^{A}(\mathrm{~A}, \phi(\mathrm{A}))$ and consequently, we prove for a given arbitrary fixed shunt resistance $R_{s h}$, that the saturation current $I_{s}$ and the ideality factor $n$ are uniquely determined in function of the photocurrent $I_{p h}$, and the series resistance $R_{s}$.

Table 7 Frontwall $\mathrm{Cu}_{2} \mathrm{~S}-\mathrm{CdS}$ solar cell's calculated I-V values by Newton's method

\begin{tabular}{cccc}
\hline $\boldsymbol{V}(\boldsymbol{V})$ & $\boldsymbol{I}_{\exp }(\boldsymbol{A})$ & $\boldsymbol{I}_{\text {Newton }}(\boldsymbol{A})$ & $\boldsymbol{D}(\%)$ \\
\hline 0.000000 & 0.0408000 & 0.040750 & 0.001226 \\
0.050000 & 0.0393 & 0.039420 & 0.003053 \\
0.100000 & 0.0373 & 0.037667 & 0.009839 \\
0.200000 & 0.0315 & 0.031870 & 0.011746 \\
0.250000 & 0.0273 & 0.027522 & 0.008131 \\
0.275000 & 0.0250 & 0.025000 & 0.000000 \\
0.300000 & 0.0225 & 0.022273 & 0.010191 \\
0.325000 & 0.0196 & 0.019362 & 0.012292 \\
0.350000 & 0.0165 & 0.016290 & 0.012891 \\
0.375000 & 0.0132 & 0.013075 & 0.009560 \\
0.400000 & 0.0099 & 0.009737 & 0.016740 \\
0.450000 & 0.0025 & 0.002748 & 0.099200 \\
0.469000 & 0.000000 & 0.000000 & 0.000000 \\
\hline
\end{tabular}




\section{Experimental and theoretical results, discussion of related authenticity}

Tables 2 and 3 list the intrinsic electrical parameters values of the two cells determined by Newton's method and Hooke-Jeeves's.
To prove the authenticity of the model, we should calculate the current $I$ listed as $I_{t h}$ by the use of the obtained intrinsic parameters at different points of the I-V curves. These points are compared with the corresponding experimental current values

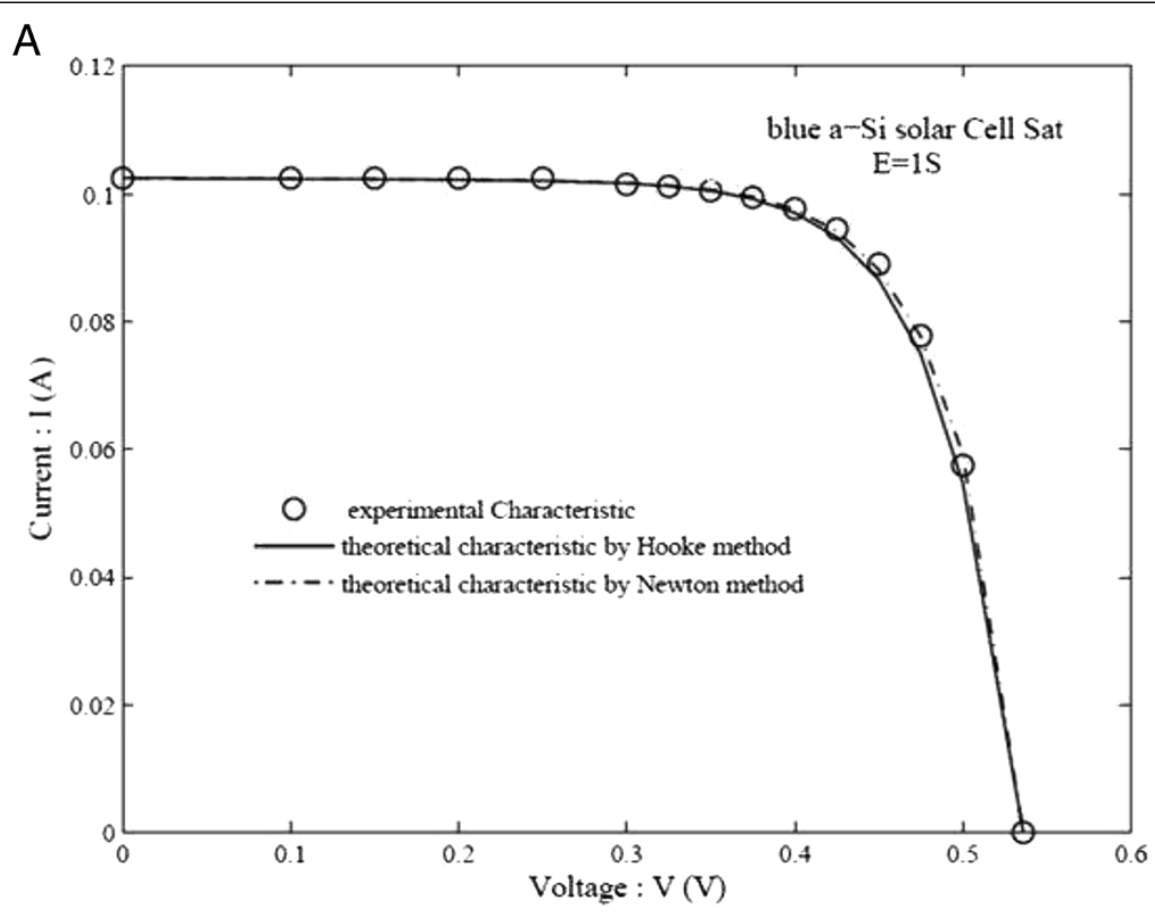

B

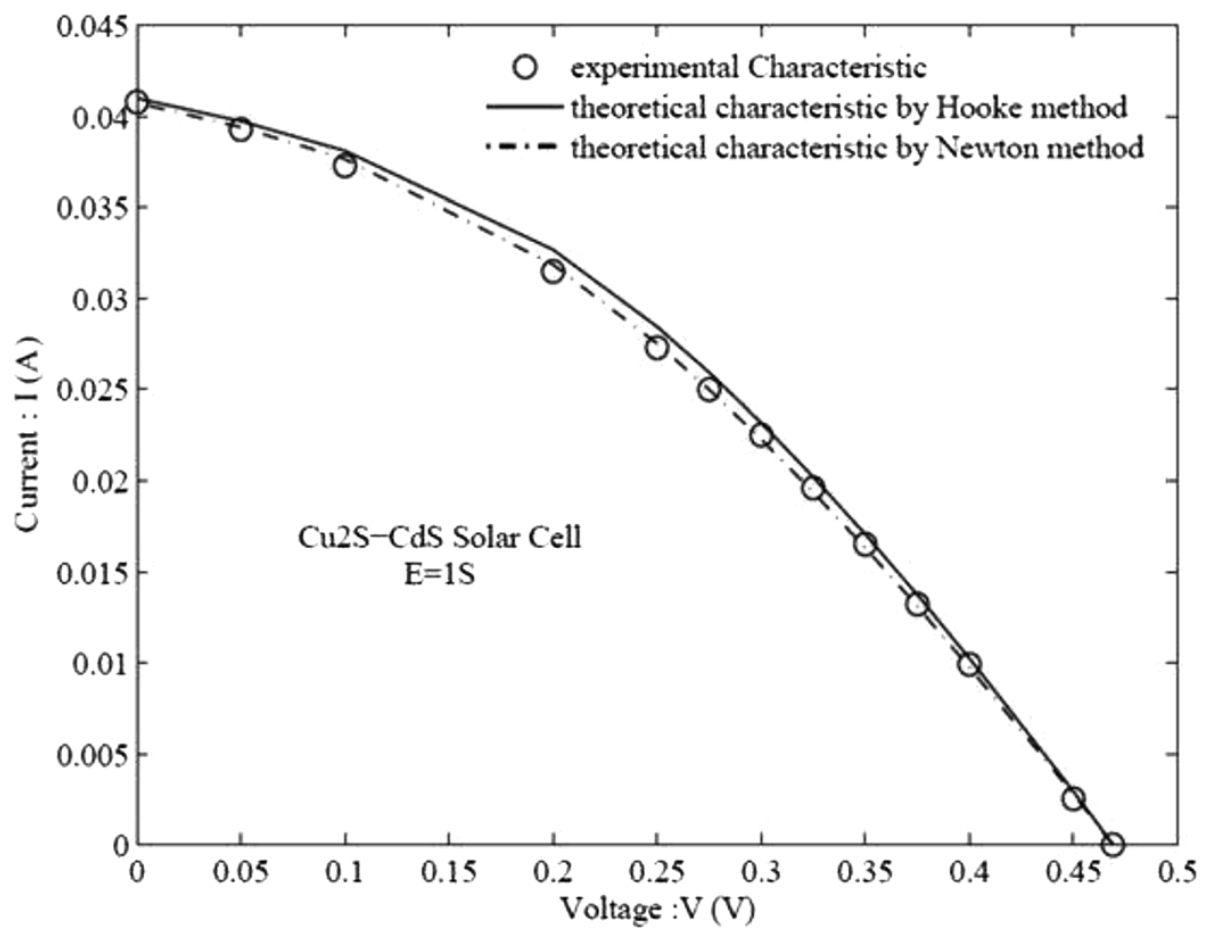

Figure 4 Experimental I-V Characteristics. (A) c-Si blue SAT solar cell. (B) Frontwall Cu2S-CdS solar cell. 
listed as $I_{\text {exp }}$. The accuracy is evaluated by the parameter $D(\%)$. The values of the called accuracy $D$ (\%) corresponding to the percentage deviation between experimental and theoretical results are also listed in Tables 4, 5, 6 and 7 and does not exceed $0.2 \%$.

A

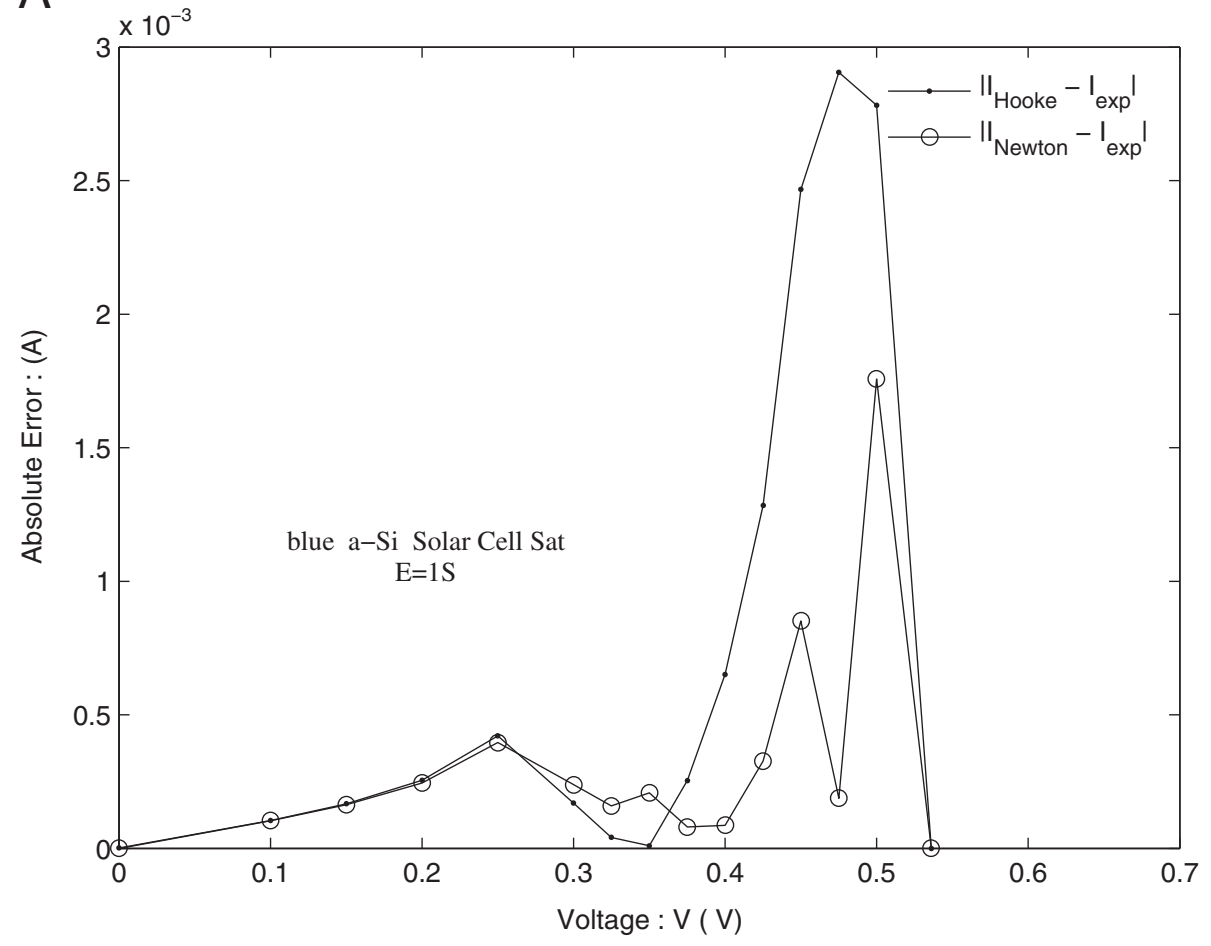

B

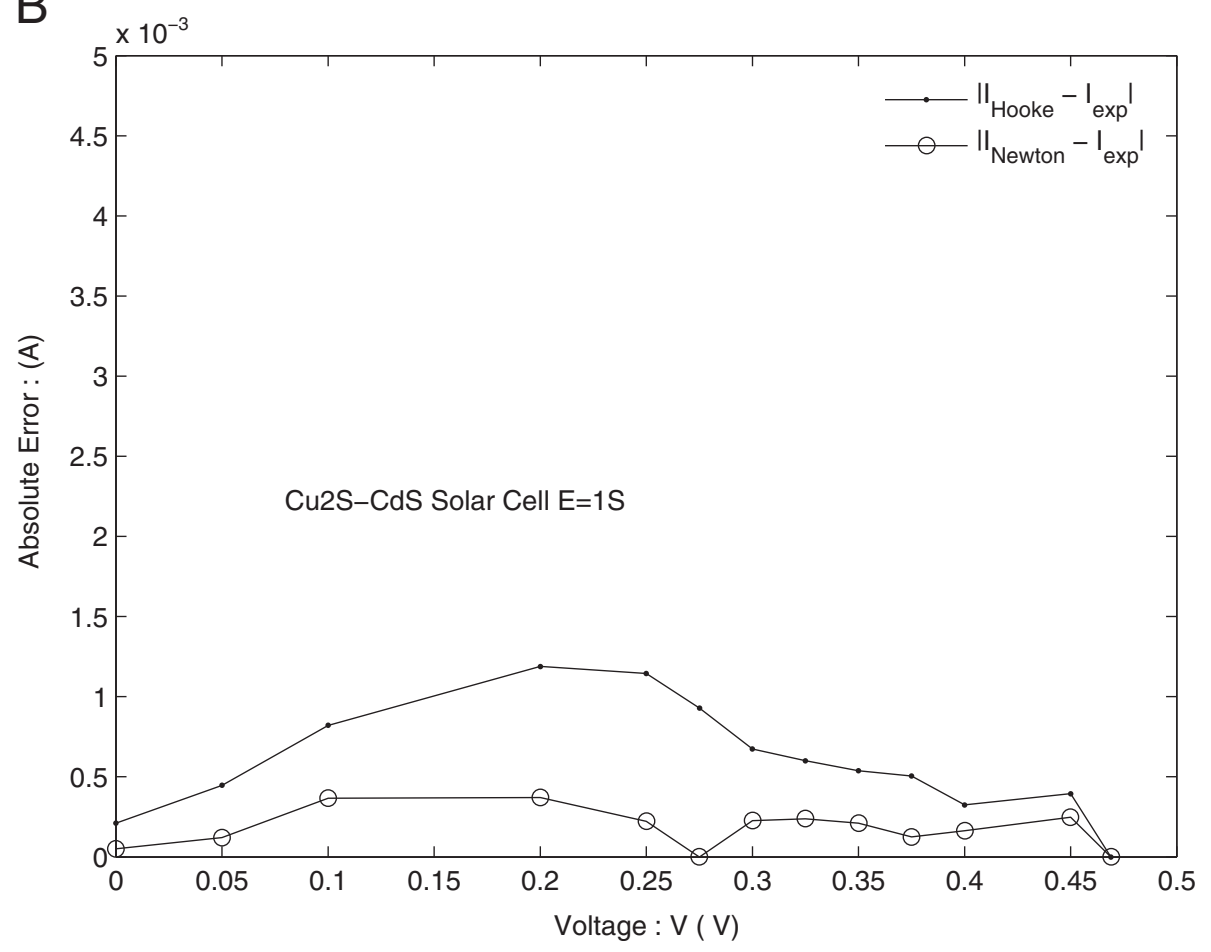

Figure 5 Absolute error between experimental and calculated current. (A) c-Si blue SAT solar cell. (B) Frontwall Cu2S CdS solar cell. 
The graphs presented in Figure 4A and B show how close the values calculated by the two used numerical methods to the experimental ones.

These figures are very sensitive to the effects of the circuit parameters with localized constants and especially to the quality of the cell. Figure 5A and B outline the absolute errors between the experimental and calculated current as a function of the cell bias voltage by the two numerical methods. Although $D$ values of the SAT solar cell in the state of the art are weaker than those of $\mathrm{Cu}_{2} \mathrm{~S}-\mathrm{CdS}$ solar cell with significant losses; absolute error (Figure 5A) goes to a maximum at $V_{o c}$-neighborhood. This maximum is weaker in the case of Newton's method, so denoting a better convergence of this method compared to Hooke's. Although in the case of the $\mathrm{Cu}_{2} \mathrm{~S}-\mathrm{CdS}$ solar cell with significant losses this indeterminacy on $R_{s}$ disappears, the calculated I-V curves show a better convergence of Newton's method.

\section{Conclusion}

In this study a simple and specific method (without approximations) was proposed to extract intrinsic electrical parameters of the one-diode solar cell model under AM1 illumination (1S).

The proposed approach includes parasite and dissipative elements such as series resistance $R_{s}$ and shunt resistance $R_{\text {sh }}$.

The use of the Lambert W-function has allowed to express explicitly the current $I$ as a function of the voltage $V$ from the modified Shockley's eq. (1).

However, it is important to highlight that the proposed method is valid for all measured I-V characteristics under any illumination intensity.

The implicit functions theorem was used to demonstrate the uniqueness of the solution. The physical considerations of the problem have also been taken into account. This procedure has proved the uniqueness of the solution.

Two different numerical methods: Newton's method and Hooke-Jeeves's were used to determine these parameters and reconfirm the uniqueness of the solution.

To prove the authenticity of this extraction method, two different types of solar cell structure were used: a SAT monocrystalline silicon homostructure in the state of the art, and a frontwall $\mathrm{Cu}_{2} \mathrm{~S}-\mathrm{CdS}$ heterostructure with significant losses.

Moreover, as MATLAB has limitations toward large numbers manipulation ( $\geq \exp (100)$ ), MAPLE software was selected for this calculation.

For the two cell types, both used numerical methods converge in each of cases, towards two series of theoretical results with relative accuracy about $3 \%$ in the case of the weak series resistance.

\section{Nomenclature}

T: Thermodynamic Temperature in Kelvin (K)

$q$ : Electron Charge $=1.602 * 10^{-19} \mathrm{C}$ $k$ : Boltzmann constant $=1.38^{*} 10^{-23} \mathrm{~J} / \mathrm{K}$

$V_{T}$ : Thermal voltage $=\mathrm{kT} / \mathrm{q}$

$V_{o c}$ : Open circuit voltage

$I_{s c}$ : Short-current voltage

I: Output current

$V$ : Output voltage

$I_{\text {max }}$ : Maximum power current

$V_{\text {max }}$ : Maximum power voltage

$P_{\text {max }}:$ maximum power

$I_{p h}$ : Photocurrent

$I_{S}$ : Diode reverse saturation current

$I_{o c}$ : Calculated current at the $\left(\mathrm{V}_{\mathrm{oc}}, 0\right)$ point

$V_{s c}$ : Calculated voltage at the $\left(0, \mathrm{I}_{\mathrm{sc}}\right)$ point

$n$ : Diode quality factor

$R_{s h}$ : shunt resistance

$R_{\text {sho }}$ : Differential Resistance at the $\left(0, \mathrm{I}_{\mathrm{sc}}\right)$ point

$R_{s}$ : Series resistance

$R_{s o}$ : Differential resistance at the $\left(\mathrm{V}_{\mathrm{oc}}, 0\right)$ point

$W$ : Lambert's function

$C_{+}$: the set of complex numbers with positive real part.

Competing interests

The authors declare that they have no competing interests.

Authors' contributions

All authors read and approved the final manuscript.

Received: 26 February 2013 Accepted: 3 September 2013

Published: 20 March 2014

\section{References}

Charles J-P (1984) "Caractérisation I (V) et Fonctionnement des Photopiles" thèse d'Etat Mention Sciences. Université des Sciences et Techniques du Languedoc Académie de Montpellier, pp 26-27

Charles J-P, Abdelkrim M, Moy YH, Mialhe P (1981) A practical method of analysis of the current voltage characteristics of solar cells. Solar Cells Rev 4:169-178

Charles J-P, Mekkaoui Alaoui I, Bordure G, Mialhe P (1985) A Critical Study of the Effectiveness of the Single and Double Exponential Models for I-V Characterization of Solar Cells. Solid State Electron 28(8):807-820

Chegaar M, Azzouzi G, Mialhe P (2006) Simple Parameter Extraction Method for illuminated solar cells. Solid State Electron 50:1234-1237

Corless RM, Gonnet GH, Hare DEG, Jeffrey DJ, Knuth DE (1996) On the Lambert W Function. Adv Comput Math 5:329-359

Jain A, Kapoor A (2005) A new approach to determine the diode ideality factor of real solar cell using Lambert W-function. Sol Energy Mater Sol Cells 85:391-396

Jain A, Sharma S, Kapoor A (2006) Solar cell array parameters using Lambert W-function. Sol Energy Mater Sol Cells 90:25-31

Kim W, Choi W (2010) A novel parameter extraction method for the one diode solar cell model. Sol Energy 84:1008-1019

Monagan MB, Geddes KO, Heal KM, Vorkoetter SM, McCarron J, DeMarco P (2003) Maple 9 Advanced Programming Guide. Maplesoft, a division of Waterloo Maple Inc, Canada

Ortiz-Conde A, Garcia Sanchez FJ, Muci J (2006) New method to extract the model parameters of solar cells from the explicit analytic solutions of their illuminated I-V characteristics. Sol Energy Mater Sol Cells 90:352-361

S.A.T (1980) Société Anonyme des Télécommunications. In. 41 Rue Cantagrel, 75624 Paris Cedex 13, France. http://www.satsouvenir.fr/?p=4

doi:10.1186/2193-1801-3-152

Cite this article as: Jarray et al:: Local uniqueness solution of illuminated solar cell intrinsic electrical parameters. SpringerPlus 2014 3:152. 